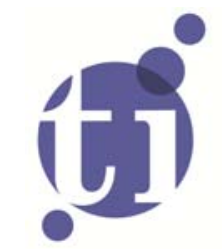

\title{
Describing the Relationships between Tourist Satisfaction and Destination Loyalty in a Segmented and Digitalized Market
}

\author{
Bart Neuts ${ }^{7}$ \\ João Romão² \\ Eveline van Leeuwen² \\ Peter Nijkamp ${ }^{2,3}$
}

\footnotetext{
1 KU Leuven, Belgium;

2 Faculty of Economics and Business Administration, VU University Amsterdam;

3 Tinbergen Institute, The Netherlands.
} 
Tinbergen Institute is the graduate school and research institute in economics of Erasmus University Rotterdam, the University of Amsterdam and VU University Amsterdam.

More TI discussion papers can be downloaded at http://www.tinbergen.nl

Tinbergen Institute has two locations:

Tinbergen Institute Amsterdam

Gustav Mahlerplein 117

1082 MS Amsterdam

The Netherlands

Tel.: +31(0)205251600

Tinbergen Institute Rotterdam

Burg. Oudlaan 50

3062 PA Rotterdam

The Netherlands

Tel.: +31(0)10 4088900

Fax: $+31(0) 104089031$

Duisenberg school of finance is a collaboration of the Dutch financial sector and universities, with the ambition to support innovative research and offer top quality academic education in core areas of finance.

DSF research papers can be downloaded at: http://www.dsf.nl/

Duisenberg school of finance

Gustav Mahlerplein 117

1082 MS Amsterdam

The Netherlands

Tel.: +31(0)20 5258579 


\title{
Describing the relationships between tourist satisfaction and destination loyalty in a segmented and digitalized market
}

\author{
Bart Neuts ${ }^{1}$ \\ Dept. of Earth and Environmental Sciences \\ KU Leuven \\ bart.neuts@ees.kuleuven.be \\ João Romão \\ Dept. of Spatial Economics \\ VU University Amsterdam \\ j.romao@vu.nl \\ Eveline van Leeuwen \\ Dept. of Spatial Economics \\ VU University Amsterdam \\ e.s.van.leeuwen@vu.nl \\ Peter Nijkamp \\ Dept. of Spatial Economics \\ VU University Amsterdam \\ and Tinbergen Institute \\ p.nijkamp@vu.nl
}

\begin{abstract}
As a result of advances in ICT-services, transportation, and local development, among others, an increasing number of destinations is competing to attract both national and international visitors. Globalisation requires destinations to increase their competitiveness or risk losing out on tourist revenues. While the research into destination competitiveness and tourist loyalty is well founded, recent progress in e-services has opened new opportunities for informing and attracting visitors. This paper examines the potential effects of e-services in an inclusive model of destination loyalty towards the city of Leipzig (Germany). The results of the path analysis indicate possibilities for e-services to increase both satisfaction and loyalty, especially with regard to a number of tourist subgroups.
\end{abstract}

Keywords: Loyalty, E-services, ICT, Satisfaction, Destination Management

\section{Introduction}

Open borders, decline in transportation costs, the emergence of a leisure and entertainment culture, advanced communication systems and social media have, over the past years, instigated a rapid rise in tourist activities. According to UNWTO (2010), international tourist arrivals reached 935 million in 2010 (against 25 million in 1950). Tourism came fourth in the ranking of export categories (after fuels, chemicals, and automotive products), while tourism exports accounted for $30 \%$ of the world's exports of commercial services (UNWTO 2009). Consequently, tourism has become one of

\footnotetext{
${ }^{1}$ Corresponding author
} 
the fastest growing export sectors, generating employment, income and tax revenues for local destinations.

This extremely fast growth of tourism activities implies strong competition among different holiday destinations which offer a wide range of products and services, according to their natural, cultural, economic or political conditions. This global competitive environment calls for dedicated efforts in destination management and promotion, in order to create an attractive portfolio of tourism products and services at the local level. Clearly, the tourist sector is a heterogeneous sector, with a great diversity in destination alternatives, demand motives, apply characteristics, economic conditions and ecological impacts (see e.g. Matias et al, 2011). Strategic tourist policy has emerged as a vehicle to attract more tourists to designated destinations, supported by advanced marketing tools, e-tourism technology, environmental awareness campaigns, and image creation. A conceptual framework that maps out the manifold drivers and impact of tourism can be found in Wall and Mathieson (2006).

This process of massification that has been observed since the middle of the $20^{\text {th }}$ century has led to the creation of multiple segments for tourism demand, according to characteristics (e.g. nationality, cultural background, social status, or education), and motivations (see also Matias et al, 2011). This double process - differentiation of destinations and segmentation of tourists - raises the issue of matching the characteristics of destinations with the motivations and personal characteristics of tourists. The on-going competition between countries, regions and cities in order to attract potential tourists serves to explain the increased popularity of the concept of destination competitiveness. Destinations are to be seen as multi-attribute goods that offer a utility package to a varied set of customers. Brand policy - based on hotels, airlines, tourist facilities etc - is turned into a strategic tool for tourist policy. This also calls for the exploitation of territorial resources (human, social, ecological, historic-cultural etc.) in the regional or local tourist industry (see also Buhalis, 2000; Cracolici and Nijkamp, 2008; Crouch, 2011; Ritchie and Crouch, 2003).

Communication and marketing are two important modern tools to direct tourist flows to certain destinations. In recent years, a great variety of e-tourism tools and technologies has emerged (see e.g. Kourtit et al, 2011; van Leeuwen and Nijkamp, 2011). These tools are competitive weapons: they inform potential customers about the benefits of a given destination, but they also aim to create loyalty feelings (for return tourists and through word-of-mouth information to others).

The present paper aims to investigate the characteristics, satisfaction, and loyalty of tourists in a situation where e-tourism media are used as marketing and attraction tools. In our empirical work we will zoom in on tourist attitudes and behaviours in the city of Leipzig. This is a new and upcoming destination which, after the rehabilitation of the city, could attract an increased number of tourists. Our study attempts to analyse the relations between specific segments of the touristic demand and the specialized services to be provided in order to satisfy their needs and expectations and increase destination loyalty, on the one hand, and the use of specific channels of communication and e-services as a specialized tool to increase satisfaction and loyalty, on the other hand. A structural equations model (SEM), which has become a popular analytical and quantitative modelling tool for mapping out complex relational patterns in a multi-equation structure, will be presented, relating to the travel behaviour of tourists visiting the city of Leipzig.

\section{Tourists, motivations, satisfaction and loyalty}

In terms of destination potential and competitiveness, tourist loyalty has been considered as an extremely important aspect since it implies a very effective promotion without incurring marketing costs. Loyalty towards a destination is most often defined as the intention for repeat visits by tourists and the amount by which a travel destination is likely to be recommended to friends or family. This approach - relying primarily on measures of behavioural intent, is then directly related 
to what is often identified as the attitudinal aspect of loyalty (Dekimpe et al., 1997; Dick and Basu, 1994): the favourable attitude towards a brand or destination. However, the existence of an attitudebehavioural gap causes a favourable attitude do not necessarily translate into actual behaviour as a second dimension of loyalty. While the focus on attitudinal loyalty might thus overstate actual recommendations or return visits, this approach has most often been followed in studies concerning the relationship between destination loyalty and different location characteristics (e.g. Castro et al, 2007; Chen and Tsai, 2007; Chi and Qu, 2008; Lee 2009) or between loyalty and tourist motivations (Chen and Chen, 2010; Chen and Tsai, 2008; Lee et al, 2007; Lee and Hsu, 2011; Yoon and Uysal, 2005).

As a general starting point, different personal characteristics of tourists are taken into account in order to segment the tourism market in the destinations under analysis. This segmentation allows the identification of different types of motivational factors and different levels of satisfaction obtained by each group with the different aspects of the cities, which, in turn, has been found to influence destination loyalty (Opperman, 2000; Yoon and Uysal, 2005; Chen and Tsai, 2007). Furthermore, while it is commonly assumed that loyalty is related to the satisfaction obtained on previous visit(s), it is also generally recognized in the literature (Castro et al, 2007; Lee, 2009) that satisfaction is a multidimensional construct, obtained from different aspects of the destination.

As stressed by Chen and Tsai (2007), different motivations are normally related to different expectations and images of the city, with important implications on the levels of satisfaction obtained: in fact, the satisfaction is extremely sensitive to the expectations of the tourists before the travel and these expectations are created based on images individually developed by each visitor. According to the classification proposed by Crompton (1979), pull factors are related to the tangible characteristics of a destination (urban life, landscape, events, culture, heritage, museums or climate), thus providing an extrinsic travel motive to the tourist. Push factors, on the other hand, are related to personal, intrinsic motives for travelling such as adventure, relaxation, evasion, escape from routine, or in this study the broader categories of leisure and business. Push factors are mostly related with the decision to travel, while pull factors are related with the choice of a specific destination (Dann, 1981; Kozak, 2002; Bansal and Eiselt, 2004; Yoon and Uysal, 2005). Both push motives (as personal characteristics) and pull motives (as destination characteristics) are featured in the proposed model.

Combining the findings of these different studies in Figure 1, this work then assumes that the heterogeneity of the touristic markets is the result of the different characteristics of the tourists (individual attributes like the purpose of the travel, origin, age, education, cultural values, or other). These personal characteristics then determine the decision to travel, the choice of a destination, the expectations or the perceptions of tourists regarding the places they visit. Consequently, these are essential aspects to take into consideration for the definition of marketing strategies (Kozak and Rimmington, 2000; Castro et al, 2007; Chen and Tsai, 2007).

The architecture of the conceptual model with respect to the market segmentation of tourist types then presumes: (A1) a direct relationship between the segmentation of markets (characteristics of tourists) and loyalty; (A2) a direct relationship between the characteristics of tourists and their travel motivations; (A3) a path between these motivations and the satisfaction obtained with different aspects of the destination; and (A4) an effect of the satisfaction levels on destination loyalty. Given the narrower focus on attitudinal loyalty, it can be hypothesized that the latter relationship is more pronounced than in the case where revealed behaviour is taken as a loyalty measure (Dick and Basu, 1994). These paths in Figure 1 then contribute to the understanding of which aspects of the destination should be addressed to each specific group of tourists (Chi and Qu, 2008; Lee, 2009), considering the specific products and services they need. 


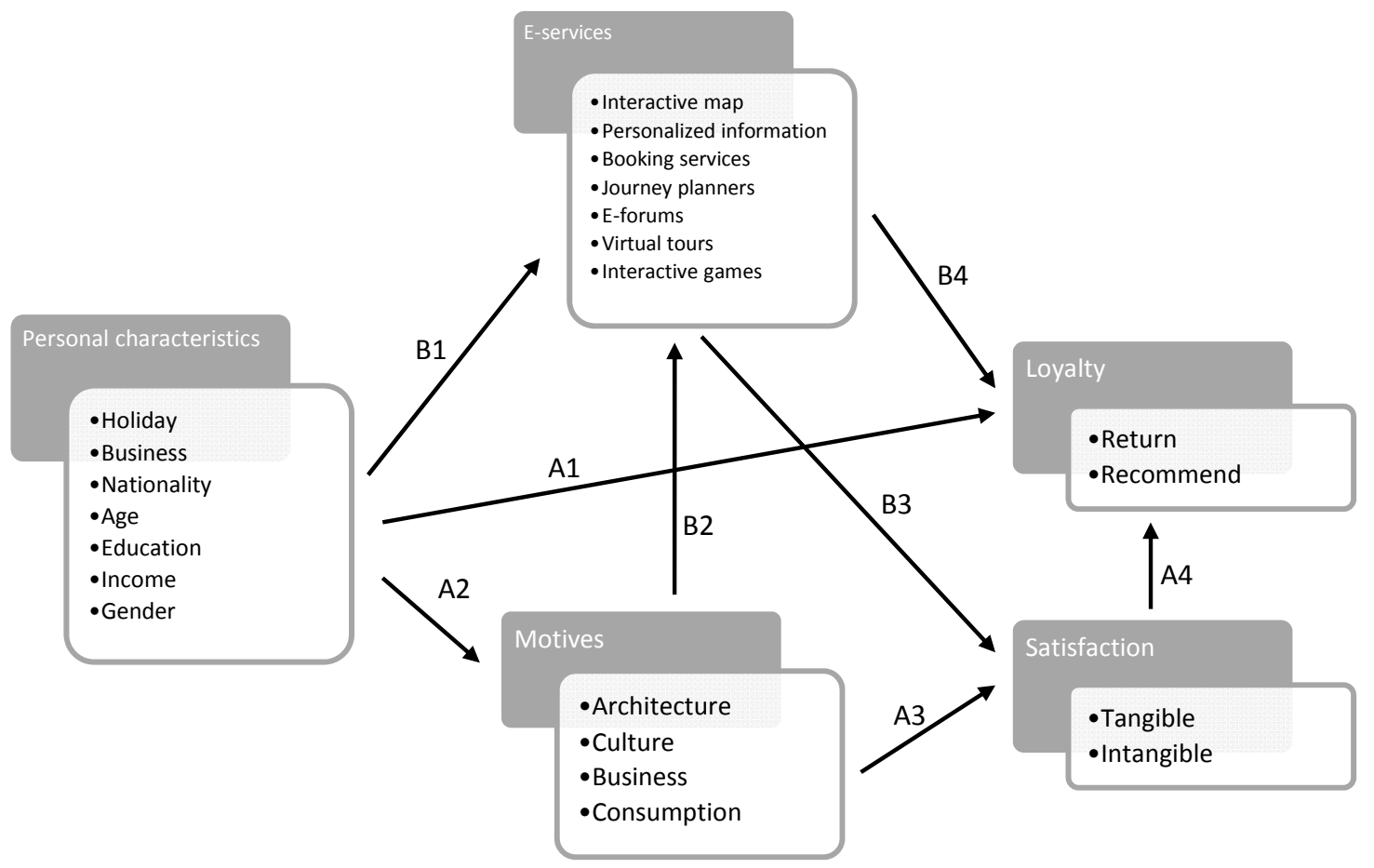

Figure 1: Conceptual structural model of tourist loyalty components

\section{The role of e-services in destination loyalty}

Aside from the influence of market segmentation on tourist loyalty, another aspect of the conceptual model is concerned with the influence that e-services can have in improving the satisfaction of and loyalty towards a destination. As a result of the deep impact on tourism of the development of information and communication technologies (ICT) in the last few decades, new sources of competitive advantage and new opportunities for marketing emerged (Singer et al, 2010), For tourism service providers and management organizations, the choice of the right channels and the production of adequate information contents is an essential aspect in order to establish an efficient communication with specific potential customers.

Various recent studies (e.g. Lin and Huang, 2006, Buhalis and Law, 2008; Aldebert et al, 2011; Chang and Caneday, 2011; Parra-Lopez et al, 2011; Lo et al, 2011; Singala et al, 2011) have analysed the processes of diffusion and collection of information in internet, focusing, for example, on the role of social networks, the websites managed by Destination Management Organizations, personal travel blogs or photography websites. These examples show the diversity of independent and complex information available for the tourists when choosing a destination and enhance the importance for an evidence-based research. Furthermore, Neuts et al (in press) found that the use of e-services was linked to diverse personal characteristics.

As noted by Mitsche et al (2008), there is an opportunity for the application of different eservices in order to increase satisfaction with diverse aspects of the destination. At least part of this potential increase in tourist satisfaction could be related to an increased awareness about the local conditions as a result of the availability of multiple e-sources, coupled with an increase in bargaining power thanks to the existence of direct communication channels with suppliers, and an improved flexibility in customer-supplier relations (Mansson, 2011). In fact, mostly with the development of social networks (Web 2.0), tourists become themselves producers of information 
regarding tourism destinations, in a context of convergence between different media supports and alternative ways of assessing media content (Jenkins, 2006).

In order to account for the effects of e-services on the market segmentation of tourists and their associated satisfaction and loyalty, three extra paths are included in the conceptual model: (B1) every tourist characteristic (i.e. holiday/business motive, nationality, age, education, income, and gender) is regressed with every e-service (i.e. interactive map, personalized information, booking services, journey planners, e-forums, virtual tours, and interactive games); (B2) it is expected that the specific travel motive could influence the e-services used by a traveller; (B3) the use of different e-services is presumed to influence the satisfaction received; and (B4) apart from an indirect effect on destination loyalty through the satisfaction, a direct effect is also hypothesized.

\section{Study methods}

The total dataset consisted of 653 national and international tourists in Leipzig, Germany. ${ }^{2}$ Important variables that are considered in this study are: personal characteristics of the tourists, their planned activities as divided over different categories, their satisfaction rates with diverse characteristics of the destination, their destination loyalty in terms of word-of-mouth and return incentive, and the use of e-services. Since the income variable included a considerable number of missing values (266), these missings were analysed and imputed through a regression estimation. Income was found to be related to the education level and the employment category, which were subsequently used for the imputation procedure. If after this procedure missings still occurred on other variables these observations were eliminated in order to have a full dataset for further analysis. The final dataset then consisted of 480 respondents.

Table 1 provides a general overview of the variables used in both models. While a number of variables were either dichotomized (gender, nationality, holiday purpose, business purpose) or measured directly on an ordinal (age, education, income) scale, Table 1 indicates that the variables motivations, satisfaction, use of e-services, and loyalty consist of multiple measurement elements.

In the case of tourist motivations and satisfaction with the destination we expect the existence of higher-order underlying dimensions, since it is well established that most destinations attract tourists for a multitude of reasons. This would mean that the motivational and satisfactional dimensions of Figure 1 consist of a number of factors (i.e. the different travel motivations and satisfaction components) that each consist of a combination of measurement items. In order to identify these sub-dimensions, exploratory factor analysis can be used. As proposed in Mulaik and Millsap's (2000) four-step modelling approach to structural equation modelling, explanatory factor analysis can be used as an important first step in order to establish the number of uni-dimensional factors out of a list of measurement items. Since the variables used in the principal component analysis were ordinal (in the case of satisfaction) or dichotomous (in the case of motivations) the exploratory factor analysis was based on the polychoric (for ordinal data) and the tetrachoric (for dichotomous data) correlation matrix, as is common in structural equation modelling (Jöreskog and Sörbom, 1996).

\footnotetext{
${ }^{2}$ The data collection took place within the Sixth Framework Programme of the European Union (FP6 EU) project, "Integrated e-Services for Advanced Access to Heritage in Cultural Tourist Destinations" (ISAAC). All surveys were carried out by trained interview teams from the University of Nottingham between August and November 2007, using both online and face-to-face interview modes.
} 
Table 1: Characteristics of the Variables Used $(n=480)$

\begin{tabular}{|c|c|c|}
\hline & Scale & Frequency / mean (sd) \\
\hline Gender (Female) & Categorical & $52.1 \%$ \\
\hline Nationality (German) & Categorical & $82.7 \%$ \\
\hline Main travel purpose & Binary (Yes/No) & \\
\hline - Holiday & & $87.9 \%$ \\
\hline - Business & & $6.7 \%$ \\
\hline - Other & & $5.4 \%$ \\
\hline Age & Ordinal & \\
\hline$-<18$ & & $2.1 \%$ \\
\hline$-18-34$ & & $35.0 \%$ \\
\hline$-35-54$ & & $41.9 \%$ \\
\hline$->54$ & & $21.0 \%$ \\
\hline Income & Ordinal & \\
\hline$-<€ 15,000$ & & $18.8 \%$ \\
\hline$-€ 15,-25,000$ & & $8.1 \%$ \\
\hline$-€ 25,-35,000$ & & $10.4 \%$ \\
\hline$-€ 35,-45,000$ & & $9.6 \%$ \\
\hline$-€ 45,-55,000$ & & $7.3 \%$ \\
\hline$->€ 55,000$ & & $9.8 \%$ \\
\hline Education & Ordinal & \\
\hline - Pre high school & & $12.7 \%$ \\
\hline - High school & & $25.2 \%$ \\
\hline - Vocational & & $19.0 \%$ \\
\hline - Bachelor degree & & $14.4 \%$ \\
\hline - Master degree & & $28.8 \%$ \\
\hline Loyalty & Binary (Yes/No) & \\
\hline - Return & & $30.0 \%$ \\
\hline - Recommend & & $32.3 \%$ \\
\hline Motivations & Binary (Yes/No) & \\
\hline - Architecture & & $73.5 \%$ \\
\hline - Museums & & $44.2 \%$ \\
\hline - Landscape & & $62.3 \%$ \\
\hline - Cultural events & & $32.3 \%$ \\
\hline - Shopping & & $42.1 \%$ \\
\hline - Business & & $5.0 \%$ \\
\hline - Nightlife & & $16.5 \%$ \\
\hline - Atmosphere & & $60.0 \%$ \\
\hline Appreciation & Ordinal (1-5) & \\
\hline - Architecture & & $4.30(0.862)$ \\
\hline - Monuments & & $3.73(1.015)$ \\
\hline - Museums & & $3.83(1.110)$ \\
\hline - Urban landscape & & $4.18(0.911)$ \\
\hline - Cultural events & & $3.66(1.133)$ \\
\hline - Traditions & & $3.44(1.112)$ \\
\hline - Customs & & $3.14(1.150)$ \\
\hline - Knowledge & & $3.20(1.130)$ \\
\hline E-services & Ordinal (1-5) & \\
\hline - Interactive map & & $3.48(1.36)$ \\
\hline - Personalized information & & $2.58(1.20)$ \\
\hline - Booking services & & $3.56(1.32)$ \\
\hline - Journey planners & & $3.38(1.28)$ \\
\hline - E-forums & & $2.58(1.23)$ \\
\hline - Virtual tours & & $2.90(1.30)$ \\
\hline - Interactive games & & $1.71(1.07)$ \\
\hline
\end{tabular}

Table 2 gives an overview of the results of these preliminary principal component analyses. Explanatory factor analysis on the tetrachoric correlation matrix of tourist activities planned appears to lead to a three-factor solution, based on the Kaiser criterion (i.e. eigenvalues above 1), 
with a cumulative explained variance of $56.977 \%$. The motivational factor is then divided into (1) an environmental motivation, incorporating the visiting purpose of architecture and landscape, (2) a cultural motive, constructed from the activities concerning museum visits and cultural events, (3) a commercial motive, based on interests for shopping, nightlife, and atmosphere. It can be seen from Table 2 that this solution does not find a significant positive correlation of the business motive with any of the three factors - being negatively related to both the first (-.449) and second (-.432) factor, and moderately unrelated (.057) to the third factor. The results therefore indicate that the business travel motive does not relate closely to other travel motives (i.e. business is not coincidental with other activities planned) and cannot be incorporated in one of the three identified factors due to a dearth of internal consistency. In order to incorporate business in the structural model, modelling results would benefit from a complete separation of this motive from the other activities. This leads to the identification of four general motives in the structural model, the three identified compounded factors of environmental motivation, cultural motivation, and commercial motivation, and one singular motive (i.e. consisting of solely planned business): business.

Table 2: Varimax Rotated Component Matrix of Principal Component Analyses

\begin{tabular}{lccc}
\hline Items & Factors & & \\
& 1 & 2 & 3 \\
\hline Motivations & .812 & -.028 & .001 \\
Activities planned architecture & -.005 & .816 & -.054 \\
Activities planned museums & .635 & .037 & -.229 \\
Activities planned landscape & -.012 & .756 & -.037 \\
Activities planned cultural events & -.247 & .158 & .661 \\
Activities planned shopping & -.449 & -.432 & .057 \\
Activities planned business & -.145 & -.310 & .708 \\
Activities planned nightlife & .507 & -.087 & .633 \\
Activities planned atmosphere & & & \\
\hline Satisfaction & .890 & -.018 & \\
Appreciation of architecture & .668 & .328 & \\
Appreciation of monuments & .749 & .222 & \\
Appreciation of museums & .645 & .124 & \\
Appreciation of urban landscape & .557 & .315 & \\
Appreciation of cultural events & .225 & .806 & \\
Appreciation of traditions & .139 & .893 & \\
Appreciation of customs & .197 & .855 & \\
Appreciation of knowledge & & & \\
\hline
\end{tabular}

The principal component analysis of satisfaction with different elements of the destination yielded a two-factor solution with a total explained variance of $63.539 \%$. The first factor (1) is concerned with the satisfaction of tangible elements (architecture, monuments, museums, urban landscape, and cultural events), with factor two (2) measuring satisfaction on intangible destination elements (traditions, customs, and knowledge). These factor scores are then incorporated in the structural path model as singular aggregated variables.

While other studies have generally treated e-services as a singular (e.g. Colesca and Dobrica, 2008; van Dijk et al, 2007) or multifactorial (e.g. Leeuwen and Nijkamp, 2010) variable, such an approach would overlook possible differences between different types of e-services on satisfaction and loyalty (Neuts et al, in press). Since multicollinearity diagnostics did not indicate a clear collinearity problem (with Variance Inflation Factors between 1.450 and 1.831, and tolerance values between 0.546 and 0.690 ), all seven e-services were treated independently in order to identify a larger number of possible relationships. 


\section{Modelling results}

After the previously described explanatory factor analysis, the structural relationships between the unidimensional variables of the conceptual model are tested in the SEM software AMOS 19.0.Apart from the structural model between destination loyalty and different tourist characteristics, a second interest of this paper lies with the possibilities offered by e-services to increase satisfaction and loyalty. While the initial path model did not show adequate fit indices $\left(\chi^{2}-\right.$ value $=156.891$ with $\mathrm{Df}=19$ and $\mathrm{p}$-value $=.000, \chi^{2} / \mathrm{Df}=8.257, \mathrm{RMSEA}=.123, \mathrm{CFI}=.943$, SRMR $=.031)$, the model was made more parsimonious on a stepwise basis, based on the t-test values of non-significant regression paths. The subsequent final path model, as shown in Figure 2 had satisfactory fit indices on all $\left(\chi^{2} / \mathrm{Df}=1.993\right.$, RMSEA $=.046$, SRMR $\left.=.041, \mathrm{CFI}=.953\right)$ but the $\chi^{2}$-test $(227.217, \mathrm{Df}=114, \mathrm{p}$-value $=.000)$. Since the latter $\chi^{2}$-statistic has been found to be biased in cases of higher sample size, departures from multivariate normality, and model complexity (Schumacker and Lomax, 2004), a model is generally accepted if other indices reach satisfactory values (for a discussion of thresholds, see Wheaton et al, 1977; Tabachnick and Fidell, 2007; Steiger, 2007).

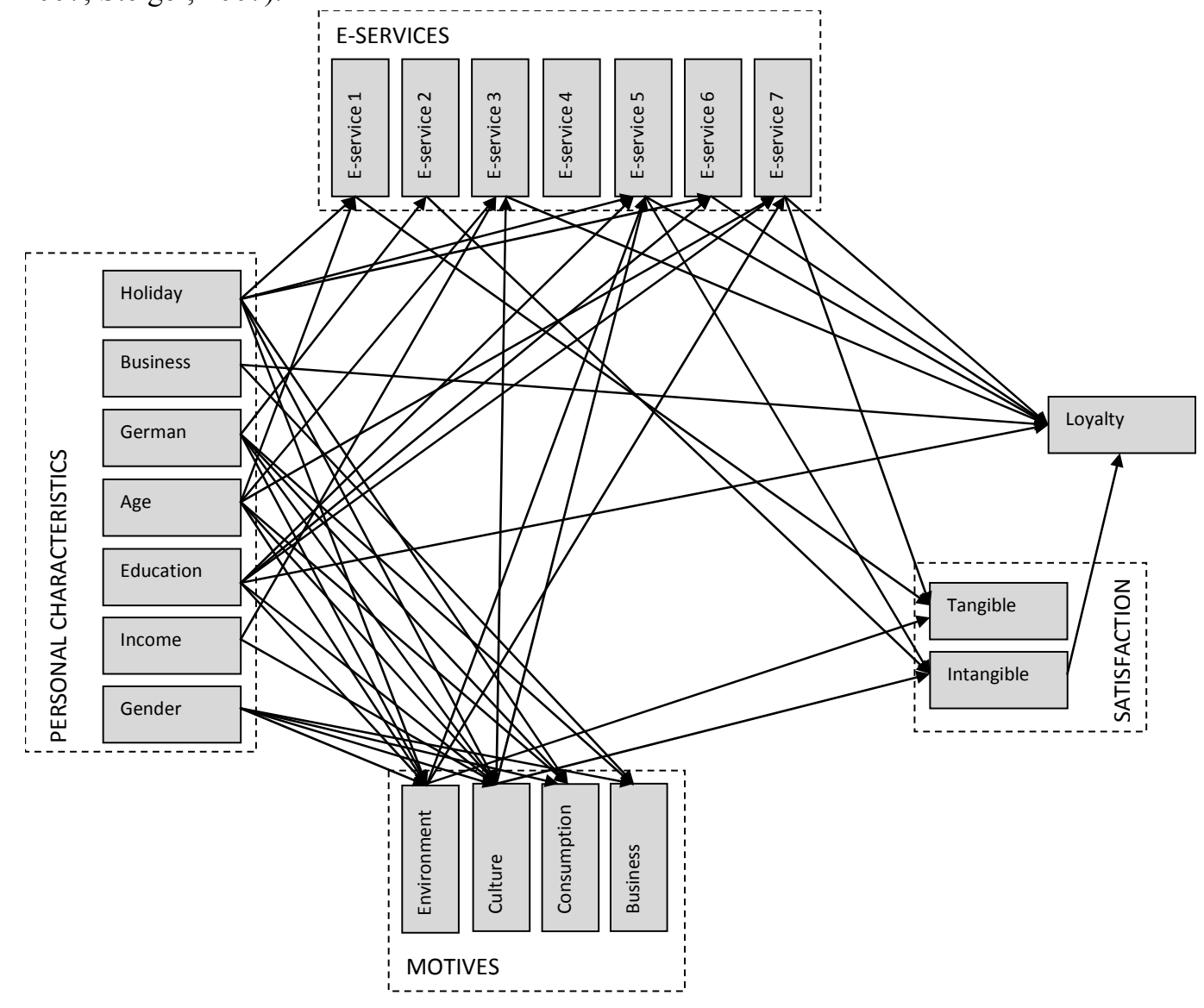

Note: For reasons of readability, covariances are not shown in the model. Only significant paths are shown. $\chi^{2}$ $=227.217(\mathrm{Df}=114, \mathrm{p}$-value $=.000), \chi^{2} / \mathrm{Df}=1.993, \mathrm{RMSEA}=.046, \mathrm{SRMR}=.041, \mathrm{CFI}=.953$.

\section{Figure 2: Operational Structural Equation Model}




\section{Empirical results of the influence on satisfaction}

In Table 3 an overview is given of the significant ${ }^{3}$ unstandardized regression estimates for the relationship between personal characteristics and travel motives. The estimation method used is based on maximum likelihood, coupled with bootstrap estimated $95 \%$ confidence intervals. According to the findings, tourists with a clear holiday purpose are more likely to be influenced by either the architectural and urban landmarks, the cultural aspects of the destination, or the shopping and nightlife possibilities in their decision to visit Leipzig. Conversely, when the primary nature of the holiday is business-related, the main travel motive is logically related to this business aspect. Older respondents are, in general, more motivated by both the environmental and the cultural aspect, while, conversely, the nightlife and shopping are seen as less important by higher age groups.

Table 3: Unstandardized Path Estimates for Personal Characteristics and Travel Motives (A2)

\begin{tabular}{lllccc}
\hline Response var. & Explanatory var. & Estimate & $\begin{array}{c}\text { Lower 95\% } \\
\text { Conf. Int. }\end{array}$ & $\begin{array}{c}\text { Upper 95\% } \\
\text { Conf. Int. }\end{array}$ & SE \\
\hline Motive Environment & Nature holiday & $.221^{* * *}$ & .044 & .233 & .043 \\
& Age & $.045^{* *}$ & .007 & .082 & .018 \\
& Gender & $.053^{*}$ & -.003 & .108 & .028 \\
& Education level & $.046^{* * *}$ & .025 & .067 & .010 \\
& German nat. & $-.154^{* * *}$ & -.236 & -.075 & .039 \\
& & & & \\
Motive Culture & Nature holiday & $.142^{* * *}$ & .044 & .233 & .052 \\
& Age & $.066^{* * *}$ & .019 & .113 & .024 \\
& Gender & $.092^{* * *}$ & .029 & .159 & .034 \\
& Income & $-.026^{* * *}$ & -.046 & -.008 & .009 \\
& Education level & $.023^{*}$ & -.002 & .049 & .013 \\
& German nat. & $-.151^{* * *}$ & -.242 & -.067 & .047 \\
Motive Consumption & Nature holiday & $.116^{* * *}$ & .036 & .194 & .038 \\
& Age & $-.08^{* * *}$ & -.116 & -.045 & .016 \\
& Gender & $.05^{* *}$ & .002 & .099 & .025 \\
& German nat. & $.101^{* * *}$ & .038 & .166 & .033 \\
& & & & \\
Motive Business & Nature business & $.412^{* * *}$ & .228 & .582 & .035 \\
& Gender & $-.032^{*}$ & -.067 & .000 & .018 \\
& German nat. & $.043^{*}$ & -.003 & .083 & .023 \\
\hline
\end{tabular}

Note: $*$ p-value $<.1, * *$ p-value $<.05, * * *$ p-value $<.01$

The data further supports a relationship between the gender of the tourist and the main travel motive, with women seemingly being more motivated by the cultural aspects, the commercial functions, and the urban environment $(\alpha<.1)$, while the business motive is more apparent among male visitors $(\alpha<.1)$, both latter relationships seemingly borderline significant as suggested by the

\footnotetext{
${ }^{3}$ Tables 3 through 7 are limited to the results that reached significance levels of at least .90. While, conventionally, a p-value of .05 is often taken as a threshold, Hoekstra et al. (2012) warn against the overreliance on this binary form of hypothesis testing - also referred to as the .05 cliff effect (Poitevineau and Lecoutre, 2001) - instead proposing the use of confidence intervals as a more informative way of significance testing. Therefore, this study will report both measures.
} 
confidence intervals. The gender effect on the business motive could be related to the specific industrial sectors located in Leipzig (e.g. car manufacturing plants, freight distribution), which are still more male-dominant, thus indicating the potential importance of accounting for the economic resource base of a destination. As could be expected from other studies, a higher education level seems to increase the tourist interest for cultural destination aspects $(\alpha<.1)$, as well as local architecture and urban design. Thus, the image of the well-educated cultural tourist is supported by the data analysis, highlighting the marketing possibilities of these elements when focussing on attracting culture tourists. On the other hand, though, the negative coefficient of income on the cultural motive implies that a higher income decreases the chance that culture is a reason for visitation.

A final factor that was found to influence all travel motives was the difference between national and international tourism. Tourists from within Germany were significantly more motivated by shopping and nightlife on the one hand, and business $(\alpha<.1)$ on the other hand. This might be related to the amount of day visits by this group as a result of its relative proximity to the destination and the significant amount of regional trade taking place. In opposition, culture and architecture were less likely to be a main travel motivation for German visitors.

Furthermore, the personal tourist characteristics were found to influence the interest in eservice availability. Table 4 gives an overview of the significant paths. The data suggests that a leisure traveller places more importance on the availability of interactive maps, e-forums, and virtual tours. It thus seems to indicate that respondents with a leisurely travel motive are increasingly likely to turn to these sources in order to find relevant information about the destination and the specific sights of interest. As could be expected, age is more negatively related to e-service adaptation, with a significant negative impact of higher age groups on the use of interactive maps, booking services and interactive games. German tourists are found to be less likely to value personalized information, possibly as a result of their larger personal knowledge of the destination. The height of one's income affects the use of booking services. A higher income thus increases the demand for online booking services. Finally, the level of education negatively impacts the importance placed on three e-services: e-forums, virtual tours, and interactive games. It is found that these services are more valued by lower educated tourists and might thus be considered to increase accessibility of information to these groups.

Table 4: Unstandardized Path Estimates for Personal Characteristics and E-services (B1)

\begin{tabular}{|c|c|c|c|c|c|}
\hline Response var. & Explanatory var. & Estimate & $\begin{array}{l}\text { Lower 95\% } \\
\text { Conf. Int. }\end{array}$ & $\begin{array}{l}\text { Upper 95\% } \\
\text { Conf. Int. }\end{array}$ & SE \\
\hline Interactive map & $\begin{array}{l}\text { Nature holiday } \\
\text { Age }\end{array}$ & $\begin{array}{l}.506^{* * *} \\
-.208^{* * *}\end{array}$ & $\begin{array}{c}.217 \\
-.347\end{array}$ & $\begin{array}{l}.795 \\
-.072\end{array}$ & $\begin{array}{l}.152 \\
.071\end{array}$ \\
\hline Personalized info & German nat. & $-.271 * * *$ & -.470 & -.069 & .106 \\
\hline Booking services & $\begin{array}{l}\text { Age } \\
\text { Income }\end{array}$ & $\begin{array}{l}-.167 * * \\
.124^{* * *}\end{array}$ & $\begin{array}{l}-.301 \\
.060\end{array}$ & $\begin{array}{l}-.038 \\
.187\end{array}$ & $\begin{array}{l}.074 \\
.032\end{array}$ \\
\hline E-forums & $\begin{array}{l}\text { Nature holiday } \\
\text { Education level }\end{array}$ & $\begin{array}{l}-.261 * * \\
-.168^{* * *}\end{array}$ & $\begin{array}{l}.054 \\
-.236\end{array}$ & $\begin{array}{l}.473 \\
-.105\end{array}$ & $\begin{array}{l}.134 \\
.033\end{array}$ \\
\hline Virtual tours & $\begin{array}{l}\text { Nature holiday } \\
\text { Education level }\end{array}$ & $\begin{array}{l}.490^{* * *} \\
-.069^{* *}\end{array}$ & $\begin{array}{l}.191 \\
-.141\end{array}$ & $\begin{array}{l}.783 \\
.000\end{array}$ & $\begin{array}{l}.159 \\
.036\end{array}$ \\
\hline Interactive games & $\begin{array}{l}\text { Age } \\
\text { Education level }\end{array}$ & $\begin{array}{l}-.125^{* *} \\
-.103^{* * *}\end{array}$ & $\begin{array}{l}-.231 \\
-.163\end{array}$ & $\begin{array}{l}-.023 \\
-.045\end{array}$ & $\begin{array}{l}.053 \\
.032\end{array}$ \\
\hline
\end{tabular}

Note: $*$ p-value $<.1, * *$ p-value $<.05, * * *$ p-value $<.01$ 
Table 5 then incorporates the significant paths between the previously identified travel motives (an environmental, cultural, commercial and business motive for travelling), and the use of e-services. As the results indicate, cultural tourists seem to have a preference for a number of eservices (booking services and e-forums) while, conversely, travellers with a main interest in the architectural and environmental landmarks value interactive services such as e-forums and interactive games less.

Table 5: Unstandardized Path Estimates for Motives and E-services (B2)

\begin{tabular}{llcccc}
\hline Response var. & Explanatory var. & Estimate & $\begin{array}{c}\text { Lower 95\% } \\
\text { Conf. Int. }\end{array}$ & $\begin{array}{c}\text { Upper 95\% } \\
\text { Conf. Int. }\end{array}$ & SE \\
\hline Booking services & Motive Culture & $.366^{* * *}$ & .106 & .625 & .130 \\
E-forums & Motive Culture & $.529 * * *$ & .216 & .855 & .137 \\
& Motive Environment & $-.504^{* * *}$ & -.853 & -.163 & .168 \\
Interactive games & Motive Environment & $-.407 * * *$ & -.652 & -.159 & .131 \\
\hline Note: $*$ p-value $<.1, * *$ p-value $<.05, * * *$ p-value $<.01$ & &
\end{tabular}

Next, Table 6 describes the results of the estimated paths between the two satisfaction factors on the one hand, and the four motivational constructs and seven e-services on the other hand. Only a limited number of proposed paths were found to be significantly related. First of all, the environmental travel motive (i.e. tourists interested in the architecture and urban landscape) was positively related to satisfaction with tangible heritage. This would seem to suggest that tourists with an interest in tangible heritage are satisfied with the urban heritage elements found in Leipzig. On the other hand, a higher cultural motivation more likely increases the satisfaction on the intangible heritage present. Both results indicate that the main travel motive of both tourist groups is in general sufficiently met in the destination city; the satisfaction rates on the corresponding destination elements increase with motivation.

The results also give insights into the potential of e-services to improve destination satisfaction. Four e-services have been found significantly positive. These can be divided into two main groups: interactive impersonal services (i.e. maps and games), and social information sources (i.e. personalized information and e-forums). It seems that satisfaction with tangible heritage can be improved by the provision of interactive maps, as well as interactive games as a means of heritage interpretation. In order to receive a superior rate of satisfaction for intangible heritage sources, visitors are more likely to depend on personalized information or e-forums. This might be an indication of the importance of social media sources, specifically for intangible heritage interpretation and appreciation.

Table 6: Unstandardized Path Estimates for Travel Motives and Satisfaction (A3 and B3)

\begin{tabular}{lllccc}
\hline Response var. & Explanatory var. & Estimate & $\begin{array}{c}\text { Lower 95\% } \\
\text { Conf. Int. }\end{array}$ & $\begin{array}{c}\text { Upper 95\% } \\
\text { Conf. Int. }\end{array}$ & SE \\
\hline Satisfaction tangible & Motive Environment & $.771^{* * *}$ & .561 & .984 & .091 \\
& Interactive map & $.090^{* * *}$ & .042 & .141 & .022 \\
& Interactive games & $.075^{* * *}$ & .016 & .131 & .029 \\
Satisfaction intangible & Motive Culture & $.320^{* * *}$ & .121 & .518 & .098 \\
& Personalized info & $.128^{* * *}$ & .050 & .206 & .036 \\
& E-forums & $.079^{*}$ & .000 & .160 & .035 \\
\hline
\end{tabular}

Note: $*$ p-value $<.1, * *$ p-value $<.05, * * *$ p-value $<.01$ 


\section{Empirical results of the influence on loyalty}

The influence of personal characteristics, satisfaction, and e-services on destination loyalty is investigated in Table 7. Seven relationships were found significant, albeit two of them only interpretable on a $90 \%$ confidence level. According to these findings, business as the main nature for travelling, education level, and satisfaction with the intangible elements of the destination all lead to a higher loyalty towards the destination. Interestingly, loyalty thus seems only marginally affected by a higher satisfaction with intangible elements, with the lower level of the $95 \%$ confidence interval hovering around zero. Since it was stated in the theoretical section that the relationship between satisfaction and loyalty might be inflated as a result of the focus on attitudinal loyalty, the link between satisfaction and actual return or recommendation behaviour might thus be very limited. The results also imply that other factors might be more influential in the formation of a destination loyalty. However, compared to the non-significance of satisfaction with tangible aspects of the city, the positive value of the intangible elements should not be overlooked. The difference between both satisfaction aspects seems to suggest that intangible aspects are better capable of providing a stand-out experience that might lead to return visits or recommendations.

Furthermore, three e-services (booking services, e-forums, and virtual tours) had a positive effect on loyalty, while the provision of interactive games seemed to have a negative effect on the possibility of a return visit or a recommendation.

Table 7: Unstandardized Path Estimates for Personal Characteristics, Satisfaction, and Loyalty (A1, A4 and B4)

\begin{tabular}{llcccc}
\hline Response var. & Explanatory var. & Estimate & $\begin{array}{c}\text { Lower 95\% } \\
\text { Conf. Int. }\end{array}$ & $\begin{array}{c}\text { Upper 95\% } \\
\text { Conf. Int. }\end{array}$ & SE \\
\hline Destination loyalty & Nature business & $.134^{* * *}$ & .053 & .227 & .056 \\
& Education level & $.036^{* * *}$ & .015 & .056 & .010 \\
& Satisfaction intangible & $.028^{*}$ & -.005 & .063 & .017 \\
& Booking services & $.052^{* * *}$ & .030 & .072 & .011 \\
& E-forums & $.049^{* * *}$ & .020 & .083 & .014 \\
& Virtual tours & $.024^{*}$ & -.002 & .051 & .012 \\
& Interactive games & $-.056^{* * *}$ & -.087 & -.026 & .015 \\
\hline
\end{tabular}

Note: $*$ p-value $<.1, * *$ p-value $<.05, * * *$ p-value $<.01$

Finally, apart from these direct relationships, a number of indirect influences on tourist loyalty could be found for the personal tourist characteristics, motivations, and e-services, as shown in Table 8 . As such, gender $(.004$; $\mathrm{p}$-value $=.024)$, income $(.005 ; \mathrm{p}$-value $=.023)$, nature holiday $(.029, \mathrm{p}$-value $=.002)$, cultural travel motive $(.055, \mathrm{p}$-value $=.001)$, and personalized information $(.004 ; \mathrm{p}$-value $=.091)$ had a further indirect positive influence on loyalty, while the German nationality had a slight indirect negative effect on loyalty $(-.007$; p-value $=.064)$, the latter two relationships only being significant on a $\alpha=.1$ level though. 
Table 8: Unstandardized Indirect effects

\begin{tabular}{llcccc}
\hline Response var. & Indirect explanatory var. & Estimate & $\begin{array}{c}\text { Lower 95\% } \\
\text { Conf. Int. }\end{array}$ & $\begin{array}{c}\text { Upper 95\% } \\
\text { Conf. Int. }\end{array}$ & SE \\
\hline Destination loyalty & Nature holiday & $.029 * * *$ & .011 & .049 & .010 \\
& Gender & $.004 * * *$ & .000 & .010 & .002 \\
& Income & $.005^{* *}$ & .001 & .010 & .002 \\
& German nat. & $-.007 *$ & -.016 & .000 & .004 \\
& Motive Culture & $.055^{* * *}$ & .026 & .091 & .016 \\
& Personalized info & $.004 *$ & -.001 & .009 & .003 \\
\hline
\end{tabular}

Note: $*$ p-value $<.1, * *$ p-value $<.05, * * *$ p-value $<.01$

\section{Concluding remarks}

The statistical results generated by the model provide an indication of the different factors that ultimately influence the satisfaction and loyalty of visitors towards the destination of Leipzig and could provide for an overview of management actions in order to increase the destination's competitiveness. This is especially important with respect to the provision of different e-services. While a destination cannot directly impact the characteristics of tourists visiting (one can only apply alternative marketing strategies), the e-services that are available to visitors are more controllable by a destination management organization.

On the level of tourist characteristics, results indicate a higher loyalty for the business segment. While this could be linked to ongoing business relations between companies and sectors of different locations, it is possible that business travellers with a favourable attitude towards the destination are more likely to later return as leisure tourists. Destination management organizations should thus not just focus on providing the business sector with adequate facilities such as conference venues, an active approach towards informing these visitors of the leisure possibilities of the city (e.g. through guided visits, information packages and location of meeting venues) might improve their lifetime value.

While satisfaction levels only seemed of minor importance in the construction of attitudinal loyalty, the fact should not be overlooked that intangible sources are more likely to lead to return or recommendation possibilities. Investments in the destination should thus not limit themselves to hardware and events created around local traditions and culture might be better capable of translating into a higher visitor loyalty. While it is difficult to diversify oneself on the basis of an authentic cultural experience, cities that can succeed in the creation of a unique atmospheric image (e.g. Amsterdam) could be found to have a competitive advantage towards regions purely focussing on developing museums and attractions.

Finally, the most direct influence might be had on the creation of e-services. Given the positive influence of booking services, e-forums and virtual tours, a destination management organization could thus benefit from either adding a booking tool to their own website, or helping local hotels, museums, and attractions to manage internet booking services. This could increase exposure and might add to the satisfaction of tourists by offering ease of access and reduce search costs or local waiting time (at attractions and museums). Furthermore, the positive effect of eforums is a statement to the importance for a destination to develop their marketing on different platforms, thereby paying attention to the viral possibilities of these e-forums. While the new digital age has made the management of an official destination image much harder, online platforms can increase direct contact with the (potential) customer and provide them with the most up-to-date information about the destination.

Furthermore, the heterogeneity of e-services used, as influenced by personal characteristics and motivations to visit, emphasizes the importance of developing specific channels and information contents for specific market segments. As such it was found that e-forums and virtual 
tours can serve in increasing information accessibility for lower educated tourists, therefore opening up this market segment. Conversely, booking services were valued more highly by higher income tourists, strengthening their loyalty towards a destination. On the other hand, a destination management organization should not overlook the fact that certain tourist groups (e.g. older aged tourists) are less likely to look for information through e-services.

Some limitations of this study and possibilities for future research can be noted. It is important to notice that the collection of data for this work has been made before the massification of the usage of social networks like Twitter or Facebook, which dramatically enhanced the possibility of the tourists to produce and share their own travel experiences, using different types of information supports. Furthermore, an extension of the loyalty aspects towards both the attitudinal and behavioural aspects can be considered in future research. By measuring intent as well as actual return behaviour, better insights can be developed into the worth of attitudinal loyalty. This would, however, require a longitudinal database over different years since return visits do not necessarily occur within a short time period. A further development of this work should take these important aspects into consideration.

\section{References}

Aldebert, B., Dang, R., and Longhi, C. (2011), 'Innovation in the tourism industry: The case of Tourism@', Tourism Management, Vol 32, pp 1204-1213.

Bansal, H.S. and Eiselt, H. (2004), 'Exploratory research of tourist motivations and planning', Tourism Management, Vol 25, pp 387-396.

Buhalis, D. (2000), 'Marketing the competitive destination of the future', Tourism Management, Vol 21, pp 97-116

Buhalis, D. and Law, R. (2008), 'Progress in information technology and tourism management: 20 years on and 10 years after the Internet-The state of eTourism research', Tourism Management, Vol 29, pp 609-623.

Castro, C., Armario, E., and Ruiz, D. (2007),'The influence of market heterogeneity on the relationship between a destination's image and tourists' future behavior', Tourism Management, Vol 28, pp 175 187.

Chang, G. and Caneday, L. (2011), 'Web-based GIS in tourism information search: Perceptions, tasks, and trip attributes', Tourism Management, Vol 32, pp 1435 -1437.

Chen, C. and Chen, F. (2010), 'Experience quality, perceived value, satisfaction and behavioral intentions for heritage tourists', Tourism Management, Vol 31, pp 29-35.

Chen, C. and Tsai, D. (2007), 'How destination image and evaluative factors affect behavioral intentions?', Tourism Management, Vol 28, pp 1115-1122.

Chen, C. and Tsai, D. (2008), 'Perceived value, satisfaction, and loyalty of TV travel product shopping: Involvement as a moderator', Tourism Management, Vol 29, pp 1166-1171.

Chi, C. and Qu, H. (2008), 'Examining the structural relationships of destination image, tourist satisfaction and destination loyalty: An integrated approach', Tourism Management, Vol 29, pp 624-636.

Colesca, S.E. and Dobrica, L. (2008), 'Adoption and use of e-government services: the case of Romania', Journal of Applied Research and Technology, Vol 6, No 3, pp 204-217.

Cracolici, M.F. and Nijkamp, P. (2008), 'The attractiveness and competitiveness of tourist destinations: A study of Southern Italian regions', Tourism Management, Vol 30, pp 336-344.

Crompton, J. (1979), 'Motivations for Pleasure Vacations', Annals of Tourism Research, Vol October/December VI(4), pp 408-424.

Crouch, G.I. (2011), 'Destination Competitiveness: An Analysis of Determinant Attributes', Journal of Travel Research, Vol 50, No 1, pp 27-45.

Dann, G. (1981), 'Tourist Motivation: An Appraisal', Annals of Tourism Research, Vol VIII, No 2, pp 187219.

Dekimpe, M.G., Steenkamp, J.-B., Mellens, M., and Abeele, P.V. (1997). 'Decline and Variability in Brand Loyalty', International Journal of Research in Marketing, Vol 14, pp 405-420.

Dick, A.S. and Basu, K. (1994). 'Customer Loyalty: Toward an Integrated Conceptual Framework', Journal of the Academy of Marketing Science, Vol 22, pp 99-113. 
Hoekstra, R., Johnson, A., and Kiers, H.A.L. (2012). 'Confidence Intervals Make a Difference: Effects of Showing Confidence Intervals on Inferential Reasoning', Educational and Psychological Measurement, Vol 72, No 6, pp 1039-1052.

Jenkins, H. (2006), Convergence culture. Where old and new media collide, New York, New York University Press.

Jöreskog, K.G., and Sörbom, D. (1996), LISREL 8: User's reference guide, Chicago, Scientific Software.

Kourtit, K., Nijkamp, P., van Leeuwen, E., and Bruinsma, F. (2011), 'Evaluation of cyber-tools in cultural tourism', International Journal of Sustainable Development, Vol 14, No 3/4, pp 179-205.

Kozak, M. and Rimmington, M. (2000), 'Tourist Satisfaction with Mallorca, Spain, as an Off-Season Holiday Destination', Journal of Travel Research, Vol 38, pp 260-269.

Kozak, M. (2002), 'Comparative analysis of tourist motivations by nationality and destinations', Tourism Management, Vol 23, pp 221-232.

Lee, C., Yoon, Y., and Lee, S. (2007), 'Investigating the relationships among perceived value, satisfaction, and recommendations: The case of the Korean DMZ', Tourism Management, Vol 28, pp 204-214.

Lee, T. and Hsu, F. (2011), 'Examining How Attending Motivation and Satisfaction Affects the Loyalty for Attendees at Aboriginal Festivals', International Journal of Tourism Research, Vol 15, No 1, pp 1834.

Lee, T. (2009), 'A Structural Model to Examine How Destination Image, Attitude, and Motivation Affect the Future Behavior of Tourists', Leisure Sciences, Vol 31, pp 215-236.

Lin, Y. and Huang, J. (2006), 'Internet blogs as a tourism marketing medium: a case study', Journal of Business Research, Vol 59, pp 1201-1205.

Mansson, M. (2011), 'Mediatized tourism', Annals of Tourism Research, Vol 38, No 4, pp 1634-1652.

Matias, A., Nijkamp, P., and Sarmento, M. (2011), Tourism Economics; Impact Analysis, Physika, Heidelberg.

Mitsche, N., Reino S., Knox, D., and Ulrike, B. (2008), 'Enhancing Cultural Tourism e-Services through Heritage Interpretation', In P. O’Connor, W. Höpken and U. Gretzel (Eds.), Information and Communication Technologies in Tourism 2008 (pp. 418-429), Springer, Vienna.

Mulaik, S.A. and Millsap, R.E. (2000), 'Doing the four-step right', Structural Equation Modeling, Vol 7, pp 36-73.

Neuts, B., Romão, J., Nijkamp, P., and van Leeuwen, E. (2012), 'Digital destinations in the tourist sector: a path model for the impact of e-services on tourist expenditures in Amsterdam', Letters in Spatial and Resource Sciences, (forthcoming).

Oppermann, M. (2000), 'Tourism Destination Loyalty', Journal of Travel Research, Vol 39, No 1, pp 78-84.

Poitevineau, J., and Lecoutre, B. (2001). 'Interpretation of significance levels by psychological researchers: The .05 cliff effect may be overstated', Psychonomic Bulletin \& Review, Vol 8, pp 847-850.

Ritchie, J.R.B. and Crouch, G.I.(2003), The Competitive Destination: a Sustainable Tourism Perspective, Wallingford, CABI.

Schumacker, R.E. and Lomax, R.G. (1996), A beginner's guide to structural equation modelling, Lawrence Erlbaum Associates, Mahwah.

Singala, M., Christou, E., and Gretzel, U. (2011), Web 2.0 in Travel, Tourism and Hospitality: Theory, Practice and Cases, Farnham, Ashgate Publishing.

Singer, P., Ferri, M., Aiello, L., and Cacia, C. (2010), 'Internet as a "point of synergy" between communication and distribution. hypothesis of model applied to tourism', International Journal of Digital Content Technology and its Applications, Vol 4, No 7, pp 23-38.

Steiger, J.H. (2007), 'Understanding the limitations of global fit assessment in structural equation modeling', Personality and Individual Differences, Vol 42, No 5, pp 893-898.

Tabachnick, B.G. and Fidell, L.S. (2007), Using Multivariate Statistics, $5^{\text {th }}$ ed, Allyn and Bacon, New York.

UNWTO (2009), Tourism Highlights, 2009 edition, Madrid, UNWTO.

UNWTO (2010), 'Resultados del turismointernacional en 2009 y perspectivaspara 2010', Madrid, Press Release 18/1/2010.

van Dijk, J., Pieterson, W., van Deuren, A., and Ebbers, W. (2007), 'E-services for citizens: the Dutch usage case', Lecture Notes in Computer Science, Vol 4656, pp 155-166.

van Leeuwen, E. And Nijkamp, P. (2010), 'A microsimulation model for e-services in cultural heritage tourism', Tourism Economics, Vol 16, No 2, 361-384. 
van Leeuwen, E. and Nijkamp, P. (2011), 'The importance of e-services in cultural tourism: an application to Amsterdam, Leipzig and Genoa', International Journal of Sustainable Development, Vol 14, No 3/4, pp 262-289.

Wall, G. and Mathieson, A. (2006), Tourism - Change, Impacts and Opportunities, Essex, Pearson Education Limited.

Wheaton, B., Muthen, B., Alwin, D.F., and Summers, G. (1977), 'Assessing Reliability and Stability in Panel Models', Sociological Methodology, Vol 8, No 1, pp 84-136.

Yoon, Y. and Uysal, M. (2005), 'An examination of the effects of motivation and satisfaction on destination loyalty: a structural model', Tourism Management, Vol 26, pp 45-56. 